OPEN ACCESS

Edited by:

Suzanne Wood,

University of Toronto, Canada

Reviewed by:

Michelle Glass,

The University of Auckland,

New Zealand

Brian F. O'Donnell,

Indiana University Bloomington,

United States

*Correspondence:

Marco Colizzi

marco.colizzi@univr.it

Specialty section:

This article was submitted to

Cognition,

a section of the journal

Frontiers in Psychology

Received: 10 January 2020

Accepted: 03 April 2020

Published: 14 May 2020

Citation:

Colizzi M, Ruggeri $M$ and

Bhattacharyya S (2020) Unraveling the Intoxicating and Therapeutic Effects of Cannabis Ingredients on

Psychosis and Cognition.

Front. Psychol. 11:833.

doi: 10.3389/fpsyg.2020.00833

\section{Unraveling the Intoxicating and Therapeutic Effects of Cannabis Ingredients on Psychosis and Cognition}

\author{
Marco Colizzi1,2*, Mirella Ruggeri' and Sagnik Bhattacharyya² \\ 1 Section of Psychiatry, Department of Neurosciences, Biomedicine and Movement Sciences, University of Verona, Verona, \\ Italy, ${ }^{2}$ Department of Psychosis Studies, Institute of Psychiatry, Psychology and Neuroscience, King's College London, \\ London, United Kingdom
}

Research evidence suggests a dose-response relationship for the association between cannabis use and risk of psychosis. Such relationship seems to reflect an increased risk of psychosis not only as a function of frequent cannabis use, but also of highpotency cannabis use in terms of concentration of $\Delta$-9-tetrahydrocannabinol ( $\Delta 9$-THC), its main psychoactive component. This finding would be in line with the evidence that $\triangle 9-\mathrm{THC}$ administration induces transient psychosis-like symptoms in otherwise healthy individuals. Conversely, low-potency varieties would be less harmful because of their lower amount of $\triangle 9$-THC and potential compresence of another cannabinoid, cannabidiol (CBD), which seems to mitigate $\triangle 9$-THC detrimental effects. A growing body of studies begins to suggest that CBD may have not only protective effects against the psychotomimetic effects of $\triangle 9-\mathrm{THC}$ but even therapeutic properties on its own, opening new prospects for the treatment of psychosis. Despite being more limited, evidence of the effects of cannabis on cognition seems to come to similar conclusions, with increasing $\triangle 9-\mathrm{THC}$ exposure being responsible for the cognitive impairments attributed to recreational cannabis use while CBD preventing such effects and, when administered alone, enhancing cognition. Molecular evidence indicates that $\triangle 9-T H C$ and CBD may interact with cannabinoid receptors with almost opposite mechanisms, with $\triangle 9$-THC being a partial agonist and $\mathrm{CBD}$ an inverse agonist/antagonist. With the help of imaging techniques, pharmacological studies in vivo have been able to show opposite effects of $\triangle 9-T H C$ and $C B D$ also on brain function. Altogether, they may account for the intoxicating and therapeutic effects of cannabis on psychosis and cognition.

Keywords: $\Delta$-9-tetrahydrocannabinol, cannabidiol, endocannabinoid system, psychosis, cognition

\section{INTRODUCTION}

Public interest in cannabis has increased over the last decade for several reasons. First, cannabis is the most popular recreational drug, and its use has increased over time, with population data estimating around 200 million users worldwide (National Academies of Sciences, 2017). Second, because of ongoing decriminalization and legalization policies (Hall and Lynskey, 2016; 
Hasin et al., 2017), low-potency cannabis varieties have come on to the market as non-medicinal products with recreational and self-medication purposes. These preparations have a legally established limit of $\Delta$-9-tetrahydrocannabinol ( $\Delta 9$-THC), the main psychoactive ingredient of cannabis, ranging from 0.2 to $1 \%$ across countries (Small, 2015). Such non-medicinal products contain mainly cannabidiol (CBD), a non-intoxicating cannabinoid (Freeman et al., 2019), at doses far lower (e.g., $25 \mathrm{mg}$ ) than those ever used in human therapeutic trials (e.g., 150-1,500 mg/d) (Davies and Bhattacharyya, 2019). Some countries have questioned the safety of these so-called "cannabis light" varieties (Sachs et al., 2015), because of wide variability in cannabinoid profiles in the absence of standardized regulations (Pavlovic et al., 2018). Third, in the illicit market, the part of the cannabis plant with the highest $\triangle 9$-THC content is selected to amplify its intoxicating effects (Small, 2015), with the result that illicit cannabis potency, indexed as $\Delta-9$-THC concentration, has increased over the last 30 years (Cascini et al., 2012). This leads to a fourth reason for public focus, as accumulating evidence indicates a dose-response relationship between increasing $\Delta 9$ THC exposure and harm attributable to or related to cannabis use (Freeman et al., 2018). Neuropsychiatric and substance use disorders account for the larger part of the burden of disease as measured in disability-adjusted life years (Gbd 2017 Risk Factor Collaborators., 2018), with psychosis and cognitive impairments representing consequences invoked as a result of high-potency cannabis use (Colizzi and Bhattacharyya, 2017; Di Forti et al., 2019). Moreover, sustained $\Delta 9$-THC exposure has been shown to drive dependence in a non-negligible proportion of users, estimated around 6-7\% (Degenhardt et al., 2013), and tolerance phenomena (Colizzi and Bhattacharyya, 2018a), by inducing neurobiological alterations in brain regions relevant to addiction (Zehra et al., 2018). Finally, a fifth reason is related to the licit production of cannabis for medicinal purposes, which has increased considerably over the last 20 years, growing from 1.4 tons in 2000, mainly for purposes of scientific research, to 211.3 tons by 2016 (International Narcotics Control Board [INC], 2019). Consistent with this, several high-income countries have implemented medicinal programs with cannabis-related medicinal products for a wide range of conditions. Sativex, a cannabis plant-derived oral spray containing $\triangle 9$-THC and CBD in a 1:1 ratio, is licensed for the treatment of multiple sclerosis spasticity in Europe, Canada, Australia, Brazil, and Israel and prescribed for chronic pain. Epidiolex, a cannabis plant-derived oral CBD solution, is licensed in the United States and Europe for treatmentresistant severe forms of childhood epilepsy. Dronabinol and nabilone, synthetic compounds chemically similar to $\triangle 9-\mathrm{THC}$, are licensed in the United States and Europe for weight loss associated with anorexia in AIDS and suboptimally controlled chemotherapy-related nausea. Estimated effectiveness of these medicinal products for the indexed indication is low (Epidiolex, dronabinol) to moderate (Sativex) (Freeman et al., 2019). Currently, clinical trials are evaluating the effectiveness of these products for different neuropsychiatric conditions, including Tourette syndrome, anxiety disorders, posttraumatic stress disorder, Alzheimer disease, Parkinson disease, psychosis, and schizophrenia (Whiting et al., 2015; National Academies of Sciences, 2017; Davies and Bhattacharyya, 2019).

Cannabis and its main ingredients have been implicated both in the development and worsening as well as in the treatment of psychosis and cognitive dysfunction. This article aims to disentangle the cannabinoid profile of different cannabis varieties with psychotogenic and intoxicating effects from that of preparations with potential therapeutic properties.

\section{METHODS}

This narrative review selectively focuses on the role of different cannabinoids in modulating psychosis and cognition. A literature search was performed using electronic databases (MEDLINE, Web of Science, and Scopus), without any time period limits, using a combination of search terms describing cannabinoids $(\triangle 9$-THC, CBD) and cognition (cognitive dysfunction/impairment/performance) or psychosis (psychotic disorder/symptoms/risk). In addition, any relevant research evidence that was not identified by this literature search has also been summarized, if considered appropriate by all authors.

\section{Cannabis, Psychosis, and Cognitive Dysfunction}

One main issue about the association between cannabis and psychosis is its nature, namely, whether it reflects a causal relationship (Colizzi and Murray, 2018). In this perspective, longitudinal studies evaluating whether cannabis use leads to subsequent development of psychosis are of particular interest. Of 13 studies conducted so far, 10 support an increased risk of subsequently developing psychosis among cannabis users (Andreasson et al., 1987; Tien and Anthony, 1990; Arseneault et al., 2002; van Os et al., 2002; Weiser et al., 2002; Zammit et al., 2002; Fergusson et al., 2003; Ferdinand et al., 2005; Henquet et al., 2005; Manrique-Garcia et al., 2012; Rognli et al., 2015; Bechtold et al., 2016). Three more studies find a trend in the same direction failing to reach statistical significance, possibly because of short follow-up periods (Wiles et al., 2006; Gage et al., 2014) or limited sample power (Rossler et al., 2012).

Some of these studies indicate a higher likelihood of developing psychosis as a function of frequent cannabis use, a good proxy for increasing $\triangle$-9-THC exposure (Tien and Anthony, 1990; Arseneault et al., 2002; Zammit et al., 2002; Henquet et al., 2005; Wiles et al., 2006), also confirmed by metaanalytic work (Marconi et al., 2016). Moreover, escalation of cannabis use in the immediate 5-year premorbid period increases the risk of psychosis onset (Kelley et al., 2016), with daily and high-potency cannabis use accounting, at least in part, for the higher incidence of psychosis found in some European countries (Di Forti et al., 2019). Also, while patients who stop using cannabis have the most favorable course of illness (Colizzi et al., 2016a), daily and high-potency cannabis use has been associated with higher (Schoeler et al., 2016b) and dose-dependent (Schoeler et al., 2016c) risk of psychosis relapse. Finally, magnetic resonance imaging (MRI) studies support a substantial overlap 
between the structural (Lorenzetti et al., 2015), functional (BlestHopley et al., 2018, 2019a,b), neurochemical (Sneider et al., 2013; Colizzi et al., 2016b; Blest-Hopley et al., 2019c), and structural connectivity (Rigucci et al., 2016) alterations observed upon frequent or high-potency cannabis use and those involved in the pathophysiology of schizophrenia (Howes et al., 2015).

Despite the evidence of a prospective association between cannabis and psychosis, it is important to highlight that alternative explanations for such association have been proposed, including the possibility that it might be accounted, at least partially, by the confounding effect of sociodemographic characteristics, preexisting psychiatric conditions, other substance use, self-medication, and shared genetic vulnerability (Colizzi and Bhattacharyya, 2020). Drawing conclusions as to whether the observed association represents a cause-effect relationship between exposure and disease is difficult (Castle, 2013; Ksir and Hart, 2016). According to epidemiological criteria to infer causality, cannabis use may be a component cause of psychosis (Castle, 2013; Colizzi and Bhattacharyya, 2020). In particular, the association appears to be of a modest strength, with the risk of psychosis being higher in heavy users carrying specific genetic or neurophysiological vulnerability, while most cannabis users do not develop psychosis (Castle, 2013; Ksir and Hart, 2016; Colizzi and Bhattacharyya, 2020).

The long-term effect of cannabis on cognition has been debated even more, because of inhomogeneous impairment across cognitive domains (Schoeler et al., 2016a; Lovell et al., 2019), genetically determined dose-response interindividual variability (Taurisano et al., 2016), and tolerance phenomena (Colizzi and Bhattacharyya, 2018a; Colizzi et al., 2018a,b). As for psychosis, evidence indicates a relationship between frequent (Meier et al., 2012) and high-potency (Colizzi and Bhattacharyya, 2017) cannabis use and the degree of cognitive impairments, supporting a cumulative adverse effect of $\triangle 9$-THC. This is particularly relevant to youth, because of more severe effects on a brain still in development (Meier et al., 2012; Blest-Hopley et al., 2018, 2019a; Hurd et al., 2019). However, cannabis use seems to have a modest overall impact on cognition (Scott et al., 2018), with the risk of more pronounced disrupting effects being higher in heavy users with specific biological and behavioral vulnerabilities (Jackson et al., 2016), while the effects are of limited clinical relevance for most individuals (Scott et al., 2018) and generally not enduring following abstinence (Schreiner and Dunn, 2012).

The exact mechanisms underlying the adverse effects of $\Delta 9$ THC and its interaction with other cannabinoids present in cannabis used recreationally remain unclear. In fact, the cannabis plant can produce at least 144 cannabinoids, whose effects are mostly unknown (Hanuš et al., 2016). In this regard, controlled experiments administering $\triangle 9$-THC and other cannabinoids to healthy people are particularly valuable. When implemented in an MRI design, such challenge studies may elucidate how different cannabinoids modulate human behavior by tracking the acute modulation of related neurobiological processes and their genetic, neurophysiological, and neuroreceptor determinants (Bhattacharyya et al., 2012a,b, 2014, 2017, 2018a).

\section{Human Laboratory Studies on Cannabinoids and Behavior}

The most compelling evidence supporting a role of cannabinoids in modulating human behavior comes from experimental studies with $\Delta$ 9-THC and CBD (Bhattacharyya et al., 2010). $\Delta$-9-Tetrahydrocannabinol can induce transient (D'Souza et al., 2004; Bhattacharyya et al., 2012b, 2015a; Colizzi et al., 2019b) and less frequently persistent psychotic symptoms needing clinical attention (D'Souza et al., 2016) in otherwise healthy individuals and worsen clinical presentation in psychosis patients (D'Souza et al., 2005). Such psychosis-inducing effect is time locked to drug administration and often occurs at the same time of a transitorily impaired cognitive functioning (Curran et al., 2002; Colizzi and Bhattacharyya, 2018b), due to perturbation of underlying brain activity (Bhattacharyya et al., 2009, 2012c). $\Delta$-9-Tetrahydrocannabinol, being a partial agonist at cannabinoid receptor 1 (CB1) (Pertwee, 2008), a potential neurobiological mechanism for its adverse behavioral effects, resides on its ability to exert a CB1-mediated facilitatory effect on striatal and prefrontal dopaminergic neurotransmission (Sami et al., 2015), possibly through a disruption of glutamate signaling (Colizzi et al., 2019a). This is in line with evidence for dopamine-glutamate aberrant interactions in psychosis and related cognitive dysfunction (Howes et al., 2015).

While $\triangle 9$-THC has shown moderate affinity for the CB1 receptor (Pertwee, 2008), synthetic cannabinoids have higher affinity, also showing full agonist action (Cohen and Weinstein, 2018). Consistent with this, risk of severe acute (Papanti et al., 2013; Castaneto et al., 2014) and long-lasting psychotic reactions for such compounds is much higher compared to $\triangle 9$-THC (Fattore, 2016; Murray et al., 2017). This is relevant, as synthetic cannabinoid recreational use has increased considerably over the last decade (Law et al., 2015).

In line with evidence that low-potency cannabis varieties with a more balanced $\triangle 9$-THC:CBD ratio are less harmful in terms of psychosis risk (Di Forti et al., 2015) and relapse (Schoeler et al., 2016b), naturalistic studies have implied less prominent acute and residual cognitive impairments in highCBD cannabis users (Morgan et al., 2010, 2012). Also, evidence is rapidly accumulating that $\mathrm{CBD}$ may prevent, reverse, or attenuate the $\triangle 9$-THC-induced aberrant behavior if administered before, after, or concomitantly (Colizzi and Bhattacharyya, 2017). This seems to reflect opposite neurophysiological effects of $\Delta$ 9-THC and CBD on prefrontal, striatal, and amygdalar substrates of psychiatric symptoms, such as psychosis and anxiety, as well as cognitive processes, such as verbal memory, response inhibition, fear processing, and auditory and visual stimuli processing (Bhattacharyya et al., 2010, 2012c, 2015b). The question arising is whether such opposite biobehavioral effects of $\triangle 9$-THC and $\mathrm{CBD}$ would reflect opposite pharmacological activities on $\mathrm{CB}$ receptors. However, the ability of $\mathrm{CBD}$ to antagonize $\mathrm{CB}$ receptors in vitro (Thomas et al., 2007) was not confirmed by subsequent evidence regarding the molecular pharmacology of CBD in vivo (Bih et al., 2015; McPartland et al., 2015). It may be possible that $\mathrm{CBD}$ affects $\mathrm{CB}$ receptor activity in vivo in an 
indirect manner, through other molecular targets such as the regulation of intracellular calcium levels (Bih et al., 2015).

Cannabidiol concentrations needed to offset any harmful effects of $\triangle 9$-THC in healthy individuals are still unclear (Colizzi and Bhattacharyya, 2017), and limited evidence suggests that CBD can exert different effects at different doses (Solowij et al., 2019). In particular, CBD seems to reduce the intoxicating effect of $\triangle 9$-THC when coadministered at the dose of $400 \mathrm{mg}$, a dose falling within tested therapeutic ranges (Davies and Bhattacharyya, 2019), while potentiating $\Delta 9$-THC-induced intoxication at the lower dose of $4 \mathrm{mg}$, a dose consistent with that allowed for non-medical use in some countries (Freeman et al., 2019). Further, the effects of cannabinoids other than $\Delta 9$ THC and CBD, which may be present at different concentrations in illicit cannabis products, are mostly unknown. This is also relevant, as for instance limited evidence indicates that pretreatment with $\Delta$-9-tetrahydrocannabivarin, a CB1 receptor neutral antagonist, prevents some of the cognitive alterations observed following acute exposure to $\triangle 9$-THC, such as impairments in delayed verbal memory recall, while exacerbating others, such as memory intrusions (Englund et al., 2016).

\section{Understanding the Role of the Endocannabinoid System in Psychosis}

Milestone discoveries in the understanding of the endocannabinoid system have been the identification of CB1 (Matsuda et al., 1990) and CB2 (Munro et al., 1993) receptors, as well as $\mathrm{N}$-arachidonoyl-ethanolamine (AEA; anandamide) (Devane et al., 1992) and 2-arachidonoylglycerol (2-AG) (Mechoulam et al., 1995), endogenous ligands at CB receptors (Di Marzo and De Petrocellis, 2012). Derivatives of the arachidonic acid, AEA is a partial agonist at CB1 and CB2 receptors, whereas 2-AG is a full agonist (Di Marzo and De Petrocellis, 2012), with both showing generally lower affinity for CB receptors than $\triangle 9$-THC (McPartland et al., 2007). Both endocannabinoids are produced on demand, and their metabolites, obtained through enzymatic hydrolysis, show biological properties (Kano et al., 2009).

Cannabinoid receptor 1 receptor signaling in the brain is essential to modulate neurotransmitter release (Colizzi et al., 2016b) and maintain neuronal activity in a balanced regimen (Zou and Kumar, 2018). The evidence that $\triangle 9$-THC, CBD, and potentially other cannabis plant-derived cannabinoids may modulate $\mathrm{CB} 1$ receptor in the brain makes them competitors of the endocannabinoids at the same receptor, with important implications for the homeostasis of the endocannabinoid system (Pertwee, 2008). An altered endocannabinoid signaling has been independently implied in psychosis (Lu and Mackie, 2016) from investigations of central nervous system biomarkers, suggesting ubiquitously higher $\mathrm{CB} 1$ receptor binding in the brain, lower levels of CB1 messenger RNA and protein in the prefrontal cortex, higher prefrontal metabolism of 2-AG, and elevated AEA levels in the cerebrospinal fluid (Volk and Lewis, 2016; Minichino et al., 2019), as well as evidence for higher AEA peripheral blood concentrations and higher $\mathrm{CB} 1$ receptor expression on peripheral immune cells (Minichino et al., 2019). Very recent evidence indicates elevated endocannabinoid levels even in the peripheral blood of people at clinical high risk (CHR) of psychosis (AppiahKusi et al., 2019), that is, people presenting with prodromal or subsyndromal psychotic symptoms suggestive of a prepsychotic phase or attenuated psychosis syndrome (Fusar-Poli et al., 2013), thus suggesting a perturbation of the endocannabinoid system in the early phases of the disorder. It is worth mentioning that studies measuring endocannabinoid levels in both the brain parenchyma and peripheral blood did not find any correlation between the alterations observed in the two body compartments (Minichino et al., 2019). Further studies are needed to investigate whether they are independently associated with psychosis.

\section{Cannabis-Based Potential Treatments for Psychosis and Cognitive Dysfunction}

Evidence that $\triangle 9$-THC and other direct-acting cannabinoid agonists can induce psychotic symptoms in both healthy individuals (Colizzi et al., 2019b) and psychosis patients (Henquet et al., 2010), and hyperactivity of the endocannabinoid system may independently promote the developmental cascade toward psychosis (Lu and Mackie, 2016), fueled the study of CB1 receptor antagonist potential in schizophrenia. Unfortunately, evidence on the efficacy of such novel compounds was disappointing (Meltzer et al., 2004). Studies also revealed important side effects of $\mathrm{CB} 1$ receptor antagonists/inverse agonists, including provoking mood alterations and suicidal ideation (Janero and Makriyannis, 2009). A promising strategy to improve the pharmacological and safety profile of $\mathrm{CB}$ receptor blockers is to shift from orthosteric to allosteric ligands. While orthosteric therapeutic compounds would compete with endocannabinoids at the $\mathrm{CB} 1$ receptor until metabolized, allosteric compounds would selectively target distinct CB1 receptor allosteric binding site(s), modulating the effect of endocannabinoids or other orthosteric ligands, such as $\triangle 9$-THC, only when and where active (Dopart et al., 2018).

In this respect, $\mathrm{CBD}$ has also been suggested to be a noncompetitive CB1 receptor antagonist, with low affinity for its primary ligand site but negative allosteric modulation properties allowing it to alter the potency of other primary ligands such as endocannabinoids and $\triangle 9$-THC in a dose-dependent manner (Laprairie et al., 2015). Despite lacking intrinsic efficacy, $\mathrm{CBD}$ would modulate the endocannabinoid tone, reducing CB1 receptor activity in the absence of the side effects previously found in CB1 inverse agonist trials (Chye et al., 2019), thus representing a promising $\mathrm{CB}$ receptor blocker. However, this potential mechanism of action does not exclude the possibility of an indirect modulation of the endocannabinoid system mediated by other molecular targets that, in conjunction with the allosteric binding, would contribute to the overall effects observed in vivo.

Not surprisingly, the antipsychotic potential of $\mathrm{CBD}$ has been the subject of evaluation since the 1990s, with 13 studies conducted so far (Davies and Bhattacharyya, 2019). Such studies widely differ in terms of study design (open-label, placebo-controlled, comparative treatment, add-on treatment), sample size $(N=1-88)$, CBD dosage $(300-1,500 \mathrm{mg} / \mathrm{d})$, length of treatment (single dose, 6 months), psychiatric 


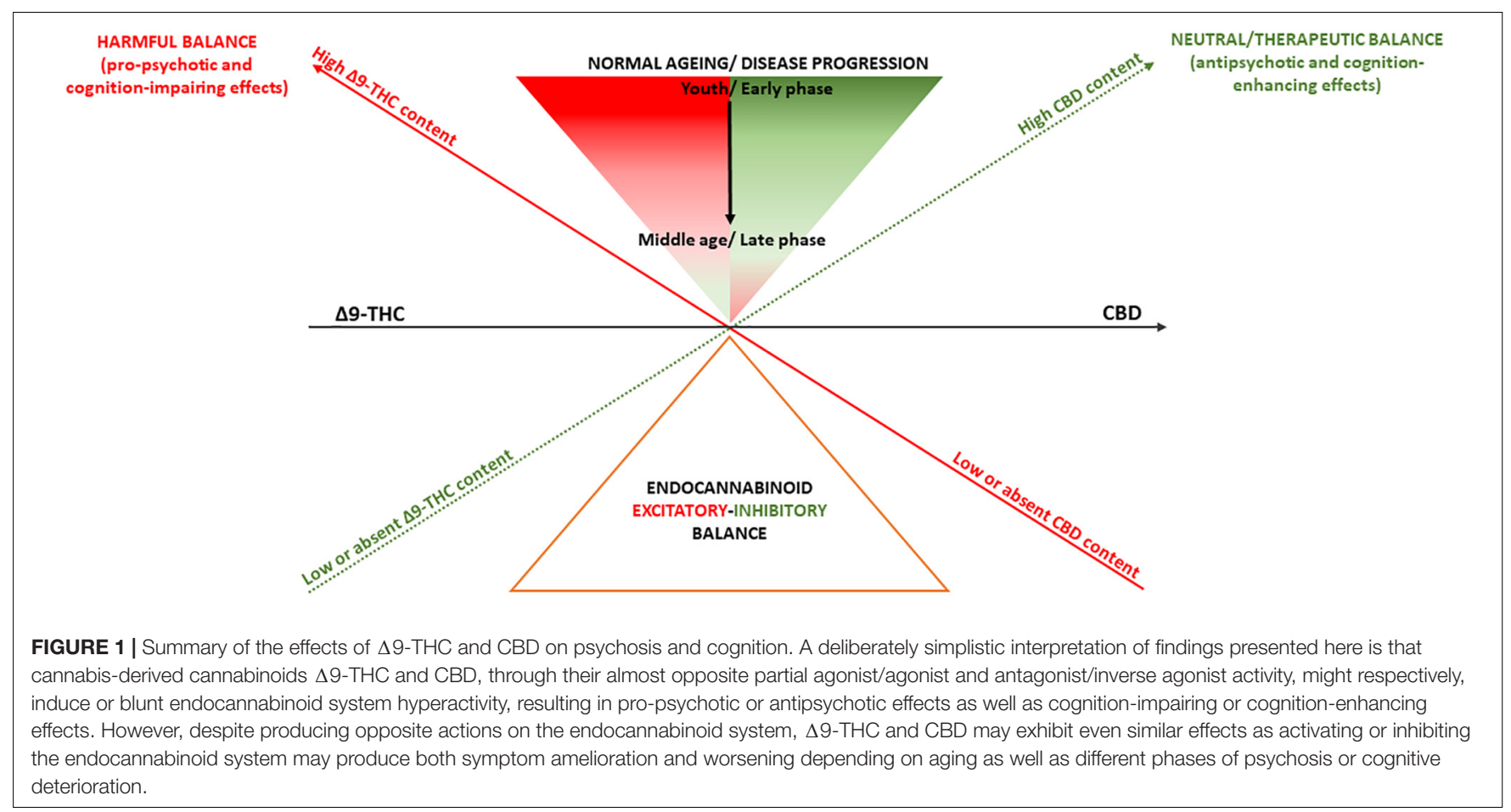

condition (schizophrenia, psychosis in Parkinson disease, CHR), and outcome measure (psychotic symptoms, psychosocial functioning, stress response, functional MRI, and cognitive processing). Early open-label case report, case series, and pilot studies indicate that a 4 -week treatment with $\mathrm{CBD}$ reduces psychotic symptoms in schizophrenia (Zuardi et al., 1995) and Parkinson disease (Zuardi et al., 2009), but not in bipolar disorder (Zuardi et al., 2010), also reducing symptom severity in 1 of 3 patients with treatment-resistant schizophrenia (Zuardi et al., 2006). The first clinical trial providing solid evidence for $C B D$ antipsychotic properties as monotherapy allocated schizophrenia patients to either CBD or the antipsychotic amisulpride up to $800 \mathrm{mg} / \mathrm{d}$ for 4 weeks, proving non-inferiority of CBD in reducing psychotic symptoms, with the advantage of a better tolerability profile (Leweke et al., 2012). Such effect of CBD in reducing psychotic symptoms was not confirmed in a subsequent study where CBD was administered at the lower dose of $600 \mathrm{mg} / \mathrm{d}$ for 2 weeks only (Leweke et al., 2014). More recently, a placebo-controlled study supported the efficacy of $1,000 \mathrm{mg} / \mathrm{d}$ CBD as add-on treatment in producing additional positive psychotic symptom reduction and overall clinical improvement in schizophrenia patients on an antipsychotic regimen for 6 weeks, with adverse events similar to placebo (McGuire et al., 2018). Another study implementing the same methodology did not replicate such add-on effect of $\mathrm{CBD}$ at the lower dose of $600 \mathrm{mg} / \mathrm{d}$ in an older population of schizophrenia patients receiving long-term polypharmacy (Boggs et al., 2018). Besides confirming a potential threshold dose-response curve, where higher CBD doses would be needed to reach antipsychotic effect (Crippa et al., 2018), it also raises the questions whether CBD may be involved in drug-to-drug interactions whose effects are unclear and whether younger patients may benefit more from CBD treatment, because of earlier intervention in the pathophysiology of psychosis. Consistent with this, recent evidence supports the efficacy of a single dose of $600 \mathrm{mg}$ CBD in normalizing aberrant brain function underlying psychotic symptoms in antipsychotic medication-naive CHR individuals (Bhattacharyya et al., 2018; Wilson et al., 2019) and early psychosis patients (O'Neill et al., 2020). Also, additional evidence indicates that a 7 -day treatment with $600 \mathrm{mg} / \mathrm{d}$ CBD may partially attenuate the altered responses to stress observed in CHR individuals (Appiah-Kusi et al., 2020). Altogether, these findings nourish hope that CBD may act as a disease-modifying drug.

Evidence for improving effects of CBD on cognition reveals a less linear dose-response effect (Davies and Bhattacharyya, 2019). In a study of cognition in schizophrenia, 1-month treatment with CBD improved selective attention at the dose of $300 \mathrm{mg} / \mathrm{d}$, while being less effective at the higher dose of $600 \mathrm{mg} / \mathrm{d}$, possibly because of sedative effects in the higher-dose group (Hallak et al., 2010). In another study, the same $600 \mathrm{mg} / \mathrm{d}$ regimen did not improve cognition among schizophrenia patients after 6 weeks of add-on treatment (Boggs et al., 2018). Also, an add-on dose of $1,000 \mathrm{mg} / \mathrm{d}$, the highest ever tested for cognitive effects in psychosis, failed to improve cognition significantly in a 6week schizophrenia trial (McGuire et al., 2018). Interestingly, a recent study indicates that a $400 \mathrm{mg} \mathrm{CBD}$ dose, while protecting against the intoxicating effects of $\Delta 9$-THC, exhibits intoxicating potential on its own in healthy individuals (Solowij et al., 2019). Limited evidence also supports the ability of low CBD doses as $16 \mathrm{mg}$ to improve emotional recognition acutely when administered to cannabis users (Hindocha et al., 2015). Altogether, compared to the effects of CBD on psychosis, 
evidence points in the direction of a narrower and potentially bell-shaped dose-response for the effects of CBD on cognition, with enhancing effects at low doses, which diminish to the extent of inducing intoxication/impairments at higher doses (Linares et al., 2019).

\section{DISCUSSION}

The endocannabinoid system modulates a wide range of biological processes through life, ranging from neurodevelopment to neurodegeneration (Di Marzo et al., 2015). It is thus plausible that pharmacological manipulation of the endocannabinoid signaling, depending on the direction of its effects (Pertwee, 2008), may have either deleterious consequences or therapeutic advantages. Consistent with this, depending on their $\triangle 9$-THC:CBD ratio, cannabis-derived drugs may have both pro-psychotic and antipsychotic as well as cognition-impairing and cognition-enhancing effects (Lu and Mackie, 2016; Figure 1). However, it is important to note that such model to explain the effects of cannabis on psychosis and cognition does not necessarily apply to other medical conditions. For instance, evidence points in the direction of a potential therapeutic role of $\triangle 9$-THC in multiple sclerosis spasticity, chronic pain management, weight loss associated with anorexia in AIDS, and chemotherapy-related nausea (Freeman et al., 2019).

Also, the endocannabinoid system function may change physiologically because of normal aging or be affected earlier in life in response to a neuropsychiatric condition and differently depending on its phases (Di Marzo et al., 2015). This has implications for the homeostasis of other neurotransmitter systems, such as glutamate and dopamine, which also go through dynamic changes in health (Kaiser et al., 2005; Rothmond et al., 2012) and disease (Howes et al., 2015). It is therefore not unreasonable to speculate that $\triangle 9$-THC and CBD effects may vary depending on patients' aging and disease progression (Di Marzo et al., 2015). Limited preclinical evidence suggests that low

\section{REFERENCES}

Andreasson, S., Allebeck, P., Engstrom, A., and Rydberg, U. (1987). Cannabis and schizophrenia. A longitudinal study of Swedish conscripts. Lancet. 2, 1483-1486. doi: 10.1016/s0140-6736(87)92620-1

Appiah-Kusi, E., Petros, N., Wilson, R., Colizzi, M., Bossong, M. G., Valmaggia, L., et al. (2020). Effects of short-term cannabidiol treatment on response to social stress in subjects at clinical high risk of developing psychosis. Psychopharmacology 237, 1121-1130. doi: 10.1007/s00213-019-05442-6

Appiah-Kusi, E., Wilson, R., Colizzi, M., Foglia, E., Klamerus, E., Caldwell, A., et al. (2019). Childhood trauma and being at-risk for psychosis are associated with higher peripheral endocannabinoids. Psychol. Med. doi: 10. 1017/S0033291719001946 [Online ahead of print]

Arseneault, L., Cannon, M., Poulton, R., Murray, R., Caspi, A., and Moffitt, T. E. (2002). Cannabis use in adolescence and risk for adult psychosis: longitudinal prospective study. BMJ 325, 1212-1213. doi: 10.1136/bmj.325.7374.1212

Bechtold, J., Hipwell, A., Lewis, D. A., Loeber, R., and Pardini, D. (2016). Concurrent and sustained cumulative effects of adolescent marijuana use on subclinical psychotic symptoms. Am. J. Psychiatry 173, 781-789. doi: 10.1176/ appi.ajp.2016.15070878 $\triangle 9$-THC doses may reverse the age-related decline in cognitive performance, while still impairing performance in youth (BilkeiGorzo et al., 2017). On the other hand, CBD does not seem to produce additional benefit as add-on treatment for psychosis patients in their middle age ( $\geq 45$ years) (Boggs et al., 2018), while ameliorating psychosis and tending to improve cognition (McGuire et al., 2018), as well as normalizing underlying neurophysiological processes (Bhattacharyya et al., 2018b) in earlier phases of the disorder (Figure 1).

Overall, evidence discussed here provides clarification for the multifaceted effects of cannabis on psychosis and cognition, by also navigating the complex role of the endocannabinoid system in both the harmful and therapeutic effects of cannabisrelated products. These considerations provide a stepping-stone to the development of cannabinoid treatments for symptom amelioration and disease modification in psychosis. However, despite being promising, research in this field is still in its infancy, and we are far from clear-cut evidence that cannabinoids have a therapeutic role in psychosis or any other mental disorder (Black et al., 2019). Future research will need to optimize the pharmacological manipulation of the endocannabinoid signaling, before any cannabis-related medical product for the treatment of psychosis and cognitive impairment might actually make it to the market.

\section{AUTHOR CONTRIBUTIONS}

All authors wrote and edited the manuscript. MC provided leadership for decisions of content, framing, and style and led the creation of the figure.

\section{ACKNOWLEDGMENTS}

This study has been carried out with the support of the Section of Psychiatry, University of Verona.

Bhattacharyya, S., Atakan, Z., Martin-Santos, R., Crippa, J. A., Kambeitz, J., Malhi, S., et al. (2015a). Impairment of inhibitory control processing related to acute psychotomimetic effects of cannabis. Eur. Neuropsychopharmacol. 25, 26-37. doi: 10.1016/j.euroneuro.2014.11.018

Bhattacharyya, S., Falkenberg, I., Martin-Santos, R., Atakan, Z., Crippa, J. A., Giampietro, V., et al. (2015b). Cannabinoid modulation of functional connectivity within regions processing attentional salience. Neuropsychopharmacology 40, 1343-1352. doi: 10.1038/npp.2014.258

Bhattacharyya, S., Atakan, Z., Martin-Santos, R., Crippa, J. A., and McGuire, P. K. (2012a). Neural mechanisms for the cannabinoid modulation of cognition and affect in man: a critical review of neuroimaging studies. Curr. Pharm. Des. 18, 5045-5054. doi: 10.2174/138161212802884636

Bhattacharyya, S., Atakan, Z., Martin-Santos, R., Crippa, J. A., Kambeitz, J., Prata, D., et al. (2012b). Preliminary report of biological basis of sensitivity to the effects of cannabis on psychosis: AKT1 and DAT1 genotype modulates the effects of $\delta$-9-tetrahydrocannabinol on midbrain and striatal function. Mol. Psychiatry 17, 1152-1155. doi: 10.1038/mp.2011.187

Bhattacharyya, S., Crippa, J. A., Allen, P., Martin-Santos, R., Borgwardt, S., Fusar-Poli, P., et al. (2012c). Induction of psychosis by Delta9tetrahydrocannabinol reflects modulation of prefrontal and striatal function 
during attentional salience processing. Arch. Gen. Psychiatry 69, 27-36. doi: 10.1001/archgenpsychiatry.2011.161

Bhattacharyya, S., Egerton, A., Kim, E., Rosso, L., Riano Barros, D., Hammers, A., et al. (2017). Acute induction of anxiety in humans by delta-9tetrahydrocannabinol related to amygdalar cannabinoid-1 (CB1) receptors. Sci. Rep. 7:15025. doi: 10.1038/s41598-017-14203-14204

Bhattacharyya, S., Fusar-Poli, P., Borgwardt, S., Martin-Santos, R., Nosarti, C., O'Carroll, C., et al. (2009). Modulation of mediotemporal and ventrostriatal function in humans by delta9-tetrahydrocannabinol: a neural basis for the effects of cannabis sativa on learning and psychosis. Arch. Gen. Psychiatry 66, 442-451. doi: 10.1001/archgenpsychiatry.2009.17

Bhattacharyya, S., Iyegbe, C., Atakan, Z., Martin-Santos, R., Crippa, J. A., Xu, X., et al. (2014). Protein kinase B (AKT1) genotype mediates sensitivity to cannabis-induced impairments in psychomotor control. Psychol. Med. 44, 3315-3328. doi: 10.1017/S0033291714000920

Bhattacharyya, S., Morrison, P. D., Fusar-Poli, P., Martin-Santos, R., Borgwardt, S., Winton-Brown, T., et al. (2010). Opposite effects of delta-9-tetrahydrocannabinol and cannabidiol on human brain function and psychopathology. Neuropsychopharmacology 35, 764-774. doi: $10.1038 /$ npp.2009.184

Bhattacharyya, S., Sainsbury, T., Allen, P., Nosarti, C., Atakan, Z., Giampietro, $\mathrm{V}$., et al. (2018a). Increased hippocampal engagement during learning as a marker of sensitivity to psychotomimetic effects of $8-9$-THC. Psychol. Med. 48, 2748-2756. doi: 10.1017/S0033291718000387

Bhattacharyya, S., Wilson, R., Appiah-Kusi, E., O’Neill, A., Brammer, M., Perez, J., et al. (2018b). Effect of cannabidiol on medial temporal, midbrain, and striatal dysfunction in people at clinical high risk for psychosis: a randomized clinical trial. JAMA Psychiatry 75, 1107-1117. doi: 10.1001/jamapsychiatry.2018.2309

Bih, C. I., Chen, T., Nunn, A. V., Bazelot, M., Dallas, M., and Whalley, B. J. (2015). Molecular targets of cannabidiol in neurological disorders. Neurotherapeutics 12, 699-730. doi: 10.1007/s13311-015-0377-3

Bilkei-Gorzo, A., Albayram, O., Draffehn, A., Michel, K., Piyanova, A., Oppenheimer, H., et al. (2017). A chronic low dose of delta9tetrahydrocannabinol (THC) restores cognitive function in old mice. Nat. Med. 23, 782-787. doi: 10.1038/nm.4311

Black, N., Stockings, E., Campbell, G., Tran, L. T., Zagic, D., Hall, W. D., et al. (2019). Cannabinoids for the treatment of mental disorders and symptoms of mental disorders: a systematic review and meta-analysis. Lancet Psychiatry 6, 995-1010. doi: 10.1016/S2215-0366(19)30401-8

Blest-Hopley, G., Giampietro, V., and Bhattacharyya, S. (2018). Residual effects of cannabis use in adolescent and adult brains - A meta-analysis of fMRI studies. Neurosci. Biobehav. Rev. 88, 26-41. doi: 10.1016/j.neubiorev.2018.03.008

Blest-Hopley, G., Giampietro, V., and Bhattacharyya, S. (2019a). Regular cannabis use is associated with altered activation of central executive and default mode networks even after prolonged abstinence in adolescent users: results from a complementary meta-analysis. Neurosci. Biobehav. Rev. 96, 45-55. doi: 10.1016/ j.neubiorev.2018.10.026

Blest-Hopley, G., O'Neill, A., Wilson, R., Giampietro, V., and Bhattacharyya, S. (2019b). Disrupted parahippocampal and midbrain function underlie slower verbal learning in adolescent-onset regular cannabis use. Psychopharmacology doi: 10.1007/s00213-019-05407-9 [Online ahead of print]

Blest-Hopley, G., O’Neill, A., Wilson, R., Giampietro, V., Lythgoe, D., Egerton, A., et al. (2019c). Adolescent-onset heavy cannabis use associated with significantly reduced glial but not neuronal markers and glutamate levels in the hippocampus. Addict. Biol. doi: 10.1111/adb.12827 [Online ahead of print]

Boggs, D. L., Surti, T., Gupta, A., Gupta, S., Niciu, M., Pittman, B., et al. (2018). The effects of cannabidiol (CBD) on cognition and symptoms in outpatients with chronic schizophrenia a randomized placebo controlled trial. Psychopharmacology 235, 1923-1932. doi: 10.1007/s00213-018$4885-9$

Cascini, F., Aiello, C., and Di Tanna, G. (2012). Increasing delta-9tetrahydrocannabinol (Delta-9-THC) content in herbal cannabis over time: systematic review and meta-analysis. Curr. Drug. Abuse Rev. 5, 32-40. doi: $10.2174 / 1874473711205010032$

Castaneto, M. S., Gorelick, D. A., Desrosiers, N. A., Hartman, R. L., Pirard, S., and Huestis, M. A. (2014). Synthetic cannabinoids: epidemiology, pharmacodynamics, and clinical implications. Drug. Alcohol Depend. 144, 1241. doi: 10.1016/j.drugalcdep.2014.08.005
Castle, D. J. (2013). Cannabis and psychosis: what causes what? F1000 Med. Rep. 5:1. doi: 10.3410/M5-1

Chye, Y., Christensen, E., Solowij, N., and Yücel, M. (2019). The endocannabinoid system and cannabidiol's promise for the treatment of substance use disorder. Front. Psychiatry 10:63. doi: 10.3389/fpsyt.2019.00063

Cohen, K., and Weinstein, A. M. (2018). Synthetic and non-synthetic cannabinoid drugs and their adverse effects: a review from public health prospective. Front. Public Health 6:162. doi: 10.3389/fpubh.2018.00162

Colizzi, M., and Bhattacharyya, S. (2017). Does cannabis composition matter? differential effects of delta-9-tetrahydrocannabinol and cannabidiol on human cognition. Curr. Addict. Rep. 4, 62-74. doi: 10.1007/s40429-017-0142-2

Colizzi, M., and Bhattacharyya, S. (2018a). Cannabis use and the development of tolerance: a systematic review of human evidence. Neurosci. Biobehav. Rev. 93, 1-25. doi: 10.1016/j.neubiorev.2018.07.014

Colizzi, M., and Bhattacharyya, S. (2018b). Neurocognitive effects of cannabis: lessons learned from human experimental studies. Prog. Brain Res. 242, 179216. doi: 10.1016/bs.pbr.2018.08.010

Colizzi, M., and Bhattacharyya, S. (2020). "Is there sufficient evidence that cannabis use is a risk factor for psychosis?," in Risk Factors for Psychosis: Paradigms, Mechanisms, and Prevention, eds A. Thompson and M. Broome (Cambridge, MA: Academic Press), 305-331. doi: 10.1016/B978-0-12-813201-2.00016-8

Colizzi, M., Carra, E., Fraietta, S., Lally, J., Quattrone, D., Bonaccorso, S., et al. (2016a). Substance use, medication adherence. Schizophr. Res. 170, 311-317. doi: 10.1016/j.schres.2015.11.016

Colizzi, M., McGuire, P., Pertwee, R. G., and Bhattacharyya, S. (2016b). Effect of cannabis on glutamate signalling in the brain: a systematic review of human and animal evidence. Neurosci. Biobehav. Rev. 64, 359-381. doi: 10.1016/j. neubiorev.2016.03.010

Colizzi, M., McGuire, P., Giampietro, V., Williams, S., Brammer, M., and Bhattacharyya, S. (2018a). Modulation of acute effects of delta-9tetrahydrocannabinol on psychotomimetic effects, cognition and brain function by previous cannabis exposure. Eur. Neuropsychopharmacol. 28, 850-862. doi: 10.1016/j.euroneuro.2018.04.003

Colizzi, M., McGuire, P., Giampietro, V., Williams, S., Brammer, M., and Bhattacharyya, S. (2018b). Previous cannabis exposure modulates the acute effects of delta-9-tetrahydrocannabinol on attentional salience and fear processing. Exp. Clin. Psychopharmacol. 26, 582-598. doi: 10.1037/pha0000221

Colizzi, M., and Murray, R. (2018). Cannabis and psychosis: what do we know and what should we do? Br. J. Psychiatry 212, 195-196. doi: 10.1192/bjp.2018.1

Colizzi, M., Weltens, N., McGuire, P., Lythgoe, D., Williams, S., Van Oudenhove, L., et al. (2019a). Delta-9-tetrahydrocannabinol increases striatal glutamate levels in healthy individuals: implications for psychosis. Mol. Psychiatry doi: 10.1038/ s41380-019-0374-8 [Epub ahead of print].

Colizzi, M., Weltens, N., McGuire, P., Van Oudenhove, L., and Bhattacharyya, S. (2019b). Descriptive psychopathology of the acute effects of intravenous delta-9-tetrahydrocannabinol administration in humans. Brain Sci. 9:E93. doi: 10.3390/brainsci9040093

Crippa, J., Guimaraes, F., Campos, A., and Zuardi, A. (2018). Translational investigation of the therapeutic potential of cannabidiol (CBD): toward a new age. Front. Immunol. 9:2009. doi: 10.3389/fimmu.2018.02009

Curran, H. V., Brignell, C., Fletcher, S., Middleton, P., and Henry, J. (2002). Cognitive and subjective dose-response effects of acute oral delta(9)tetrahydrocannabinol (THC) in infrequent cannabis users. Psychopharmacology 164, 61-70. doi: 10.1007/s00213-002-1169-0

Davies, C., and Bhattacharyya, S. (2019). Cannabidiol as a potential treatment for psychosis. Ther. Adv. Psychopharmacol. 9:2045125319881916. doi: 10.1177/ 2045125319881916

Degenhardt, L., Ferrari, A. J., Calabria, B., Hall, W. D., Norman, R. E., McGrath, J., et al. (2013). The global epidemiology and contribution of cannabis use and dependence to the global burden of disease: results from the GBD 2010 study. PLoS One 8:e76635. doi: 10.1371/journal.pone.0076635

Devane, W. A., Hanus, L., Breuer, A., Pertwee, R. G., Stevenson, L. A., Griffin, G., et al. (1992). Isolation and structure of a brain constituent that binds to the cannabinoid receptor. Science 258, 1946-1949. doi: 10.1126/science.1470919

Di Forti, M., Marconi, A., Carra, E., Fraietta, S., Trotta, A., Bonomo, M., et al. (2015). Proportion of patients in south London with first-episode psychosis attributable to use of high potency cannabis: a case-control study. Lancet Psychiatry. 2, 233-238. doi: 10.1016/S2215-0366(14)00117-5 
Di Forti, M., Quattrone, D., Freeman, T. P., Tripoli, G., Gayer-Anderson, C., Quigley, H., et al. (2019). The contribution of cannabis use to variation in the incidence of psychotic disorder across Europe (EU-GEI): a multicentre case-control study. Lancet Psychiatry 6, 427-436. doi: 10.1016/S2215-0366(19) 30048-3

Di Marzo, V., and De Petrocellis, L. (2012). Why do cannabinoid receptors have more than one endogenous ligand? Philos. Trans. R. Soc. Lond. B. Biol. Sci. 367, 3216-3228. doi: 10.1098/rstb.2011.0382

Di Marzo, V., Stella, N., and Zimmer, A. (2015). Endocannabinoid signalling and the deteriorating brain. Nat. Rev. Neurosci. 16, 30-42. doi: 10.1038/nrn3876

Dopart, R., Lu, D., Lichtman, A. H., and Kendall, D. A. (2018). Allosteric modulators of cannabinoid receptor 1: developing compounds for improved specificity. Drug Metab. Rev. 50, 3-13. doi: 10.1080/03602532.2018.1428342

D’Souza, D. C., Abi-Saab, W. M., Madonick, S., Forselius-Bielen, K., Doersch, A., Braley, G., et al. (2005). Delta-9-tetrahydrocannabinol effects in schizophrenia: implications for cognition, psychosis, and addiction. Biol. Psychiatry 57, 594608. doi: 10.1016/j.biopsych.2004.12.006

D'Souza, D. C., Perry, E., MacDougall, L., Ammerman, Y., Cooper, T., Wu, Y. T., et al. (2004). The psychotomimetic effects of intravenous delta9-tetrahydrocannabinol in healthy individuals: implications for psychosis. Neuropsychopharmacology 29, 1558-1572. doi: 10.1038/sj.npp.1300496

D’Souza, D. C., Radhakrishnan, R., Sherif, M., Cortes-Briones, J., Cahill, J., Gupta, S., et al. (2016). Cannabinoids and psychosis. Curr. Pharm. Des. 22, 6380-6391. doi: $10.2174 / 1381612822666160826105628$

Englund, A., Atakan, Z., Kralj, A., Tunstall, N., Murray, R., and Morrison, P. (2016). The effect of five day dosing with THCV on THC-induced cognitive, psychological and physiological effects in healthy male human volunteers: a placebo-controlled, double-blind, crossover pilot trial. J. Psychopharmacol. 30, 140-151. doi: 10.1177/0269881115615104

Fattore, L. (2016). Synthetic cannabinoids-further evidence supporting the relationship between cannabinoids and psychosis. Biol. Psychiatry 79, 539-548. doi: 10.1016/j.biopsych.2016.02.001

Ferdinand, R. F., Sondeijker, F., van der Ende, J., Selten, J. P., Huizink, A., and Verhulst, F. C. (2005). Cannabis use predicts future psychotic symptoms, and vice versa. Addiction 100, 612-618. doi: 10.1111/j.1360-0443.2005.01070.x

Fergusson, D. M., Horwood, L. J., and Swain-Campbell, N. R. (2003). Cannabis dependence and psychotic symptoms in young people. Psychol. Med. 33, 15-21. doi: 10.1017/s0033291702006402

Freeman, T. P., Hindocha, C., Green, S. F., and Bloomfield, M. A. P. (2019). Medicinal use of cannabis based products and cannabinoids. BMJ 365:11141. doi: $10.1136 / \mathrm{bmj} .11141$

Freeman, T. P., van der Pol, P., Kuijpers, W., Wisselink, J., Das, R. K., Rigter, S., et al. (2018). Changes in cannabis potency and first-time admissions to drug treatment: a 16-year study in the Netherlands. Psychol. Med. 48, 2346-2352. doi: $10.1017 /$ S0033291717003877

Fusar-Poli, P., Borgwardt, S., Bechdolf, A., Addington, J., Riecher-Rössler, A., Schultze-Lutter, F., et al. (2013). The psychosis high-risk state: a comprehensive state-of-the-art review. JAMA Psychiatry 70, 107-120. doi: 10. 1001/jamapsychiatry.2013.269

Gage, S. H., Hickman, M., Heron, J., Munafo, M. R., Lewis, G., Macleod, J., et al. (2014). Associations of cannabis and cigarette use with psychotic experiences at age 18: findings from the Avon Longitudinal Study of Parents and Children. Psychol. Med. 44, 3435-3444. doi: 10.1017/S0033291714000531

Gbd 2017 Risk Factor Collaborators. (2018). Global, regional, and national comparative risk assessment of 84 behavioural, environmental and occupational, and metabolic risks or clusters of risks for 195 countries and territories, 1990-2017: a systematic analysis for the Global Burden of Disease Study 2017. Lancet 392, 1923-1994. doi: 10.1016/S0140-6736(18)32225-6

Hall, W., and Lynskey, M. (2016). Evaluating the public health impacts of legalizing recreational cannabis use in the United States. Addiction 111, 1764-1773. doi: 10.1111 /add. 13428

Hallak, J. E., Machado-de-Sousa, J. P., Crippa, J. A., Sanches, R. F., Trzesniak, C., Chaves, C., et al. (2010). Performance of schizophrenic patients in the Stroop Color Word Test and electrodermal responsiveness after acute administration of cannabidiol (CBD). Rev. Bras. Psiquiatr. 32, 56-61. doi: 10.1590/s151644462010000100011
Hanuš, L. O., Meyer, S. M., Muñoz, E., Taglialatela-Scafati, O., and Appendino, G. (2016). Phytocannabinoids: a unified critical inventory. Nat. Prod. Rep. 33, 1357-1392. doi: 10.1039/c6np00074f

Hasin, D. S., Sarvet, A. L., Cerdá, M., Keyes, K. M., Stohl, M., Galea, S., et al. (2017). US adult illicit cannabis use, cannabis use disorder, and medical marijuana laws: 1991-1992 to 2012-2013. JAMA Psychiatry 74, 579-588. doi: 10.1001/ jamapsychiatry.2017.0724

Henquet, C., Krabbendam, L., Spauwen, J., Kaplan, C., Lieb, R., Wittchen, H. U., et al. (2005). Prospective cohort study of cannabis use, predisposition for psychosis, and psychotic symptoms in young people. BMJ 330:11. doi: 10.1136/ bmj.38267.664086.63

Henquet, C., van Os, J., Kuepper, R., Delespaul, P., Smits, M., Campo, J. A., et al. (2010). Psychosis reactivity to cannabis use in daily life: an experience sampling study. Br. J. Psychiatry 196, 447-453. doi: 10.1192/bjp.bp.109.072249

Hindocha, C., Freeman, T. P., Schafer, G., Gardener, C., Das, R. K., Morgan, C. J., et al. (2015). Acute effects of delta-9-tetrahydrocannabinol, cannabidiol and their combination on facial emotion recognition: a randomised, double-blind, placebo-controlled study in cannabis users. Eur. Neuropsychopharmacol. 25, 325-334. doi: 10.1016/j.euroneuro.2014.11.014

Howes, O., McCutcheon, R., and Stone, J. (2015). Glutamate and dopamine in schizophrenia: an update for the 21st century. J. Psychopharmacol. 29, 97-115. doi: $10.1177 / 0269881114563634$

Hurd, L., Manzoni, O. J., Pletnikov, M. V., Lee, F. S., Bhattacharyya, S., and Melis, M. (2019). Cannabis and the developing brain: insights into its long-lasting effects. J. Neurosci. 39, 8250-8258. doi: 10.1523/JNEUROSCI.1165-19.2019

International Narcotics Control Board [INC] (2019). Narcotic Drugs 2018. Estimated World Requirements for 2019 - Statistics for 2017. Vienna: United Nations.

Jackson, N. J., Isen, J. D., Khoddam, R., Irons, D., Tuvblad, C., Iacono, W. G., et al. (2016). Impact of adolescent marijuana use on intelligence: results from two longitudinal twin studies. Proc. Natl. Acad. Sci. U.S.A. 113, E500-E508. doi: $10.1073 /$ pnas. 1516648113

Janero, D. R., and Makriyannis, A. (2009). Cannabinoid receptor antagonists: pharmacological opportunities, clinical experience, and translational prognosis. Expert Opin. Emerg. Drugs 14, 43-65. doi: 10.1517/14728210902736568

Kaiser, L., Schuff, N., Cashdollar, N., and Weiner, M. (2005). Age-related glutamate and glutamine concentration changes in normal human brain: $\mathrm{H}$ 1 MR spectroscopy study at 4T. Neurobiol. Aging 26, 665-672. doi: 10.1016/j. neurobiolaging.2004.07.001

Kano, M., Ohno-Shosaku, T., Hashimotodani, Y., Uchigashima, M., and Watanabe, M. (2009). Endocannabinoid-mediated control of synaptic transmission. Physiol. Rev. 89, 309-380. doi: 10.1152/physrev.00019.2008

Kelley, M. E., Wan, C. R., Broussard, B., Crisafio, A., Cristofaro, S., Johnson, S., et al. (2016). Marijuana use in the immediate 5-year premorbid period is associated with increased risk of onset of schizophrenia and related psychotic disorders. Schizophr. Res. 171, 62-67. doi: 10.1016/j.schres.2016.01.015

Ksir, C., and Hart, C. L. (2016). Cannabis and psychosis: a critical overview of the relationship. Curr. Psychiatry Rep. 18:12. doi: 10.1007/s11920-015-0657-y

Laprairie, R. B., Bagher, A. M., Kelly, M. E., and Denovan-Wright, E. M. (2015). Cannabidiol is a negative allosteric modulator of the cannabinoid CB1 receptor. Br. J. Pharmacol. 172, 4790-4805. doi: 10.1111/bph.13250

Law, R., Schier, J., Martin, C., Chang, A., and Wolkin, A. (2015). Notes from the field: increase in reported adverse health effects related to synthetic cannabinoid use - United States. January-May 2015. MMWR Morb. Mortal Wkly Rep. 64, 618-619.

Leweke, F., Hellmich, M., Pahlisch, F., Kranaster, L., and Koethe, D. (2014). Modulation of the endocannabinoid system as a potential new target in the treatment of schizophrenia. Schizophr. Res. 153:S47. doi: 10.1016/S09209964(14)70153-7

Leweke, F. M., Piomelli, D., Pahlisch, F., Muhl, D., Gerth, C. W., Hoyer, C., et al. (2012). Cannabidiol enhances anandamide signaling and alleviates psychotic symptoms of schizophrenia. Transl. Psychiatry 2:e94. doi: 10.1038/tp.2012.15

Linares, I. M., Zuardi, A. W., Pereira, L. C., Queiroz, R. H., Mechoulam, R., Guimarães, F. S., et al. (2019). Cannabidiol presents an inverted U-shaped doseresponse curve in a simulated public speaking test. Braz. J. Psychiatry 41, 9-14. doi: 10.1590/1516-4446-2017-0015 
Lorenzetti, V., Solowij, N., Whittle, S., Fornito, A., Lubman, D. I., Pantelis, C., et al. (2015). Gross morphological brain changes with chronic, heavy cannabis use. Br. J. Psychiatry 206, 77-78. doi: 10.1192/bjp.bp.114.151407

Lovell, M. E., Akhurst, J., Padgett, C., Garry, M. I., and Matthews, A. (2019). Cognitive outcomes associated with long-term, regular, recreational cannabis use in adults: a meta-analysis. Exp. Clin. Psychopharmacol. doi: 10.1037/ pha0000326 [Online ahead of print]

Lu, H. C., and Mackie, K. (2016). An introduction to the endogenous cannabinoid system. Biol. Psychiatry 79, 516-525. doi: 10.1016/j.biopsych.2015.07.028

Manrique-Garcia, E., Zammit, S., Dalman, C., Hemmingsson, T., Andreasson, S., and Allebeck, P. (2012). Cannabis, schizophrenia and other non-affective psychoses: 35 years of follow-up of a population-based cohort. Psychol. Med. 42, 1321-1328. doi: 10.1017/S0033291711002078

Marconi, A., Di Forti, M., Lewis, C. M., Murray, R. M., and Vassos, E. (2016). Meta-analysis of the association between the level of cannabis use and risk of psychosis. Schizophr. Bull. 42, 1262-1269. doi: 10.1093/schbul/sbw003

Matsuda, L. A., Lolait, S. J., Brownstein, M. J., Young, A. C., and Bonner, T. I. (1990). Structure of a cannabinoid receptor and functional expression of the cloned cDNA. Nature 346, 561-564. doi: 10.1038/346561a0

McGuire, P., Robson, P., Cubala, W. J., Vasile, D., Morrison, P. D., Barron, R., et al. (2018). Cannabidiol (CBD) as an adjunctive therapy in schizophrenia: a multicenter randomized controlled trial. Am. J. Psychiatry 175, 225-231. doi: 10.1176/appi.ajp.2017.17030325

McPartland, J. M., Duncan, M., Di Marzo, V., and Pertwee, R. G. (2015). Are cannabidiol and $\Delta(9)$-tetrahydrocannabivarin negative modulators of the endocannabinoid system? A systematic review. Br. J. Pharmacol. 172, 737-753. doi: $10.1111 /$ bph.12944

McPartland, J. M., Glass, M., and Pertwee, R. G. (2007). Meta-analysis of cannabinoid ligand binding affinity and receptor distribution: interspecies differences. Br. J. Pharmacol. 152, 583-593. doi: 10.1038/sj.bjp.0707399

Mechoulam, R., Ben-Shabat, S., Hanus, L., Ligumsky, M., Kaminski, N. E., Schatz, A. R., et al. (1995). Identification of an endogenous 2-monoglyceride, present in canine gut, that binds to cannabinoid receptors. Biochem. Pharmacol. 50, 83-90. doi: 10.1016/0006-2952(95)00109-d

Meier, M. H., Caspi, A., Ambler, A., Harrington, H., Houts, R., Keefe, R. S., et al. (2012). Persistent cannabis users show neuropsychological decline from childhood to midlife. Proc. Natl. Acad. Sci. U.S.A. 109, E2657-E2664. doi: 10. 1073/pnas.1206820109

Meltzer, H. Y., Arvanitis, L., Bauer, D., Rein, W., and Meta-Trial Study Group. (2004). Placebo-controlled evaluation of four novel compounds for the treatment of schizophrenia and schizoaffective disorder. Am. J. Psychiatry 161, 975-984. doi: 10.1176/appi.ajp.161.6.975

Minichino, A., Senior, M., Brondino, N., Zhang, S. H., Godwlewska, B. R., Burnet, P. W. J., et al. (2019). Measuring disturbance of the endocannabinoid system in psychosis: a systematic review and meta-analysis. JAMA Psychiatry 76, 914-923. doi: 10.1001/jamapsychiatry.2019.0970

Morgan, C. J., Gardener, C., Schafer, G., Swan, S., Demarchi, C., Freeman, T. P., et al. (2012). Sub-chronic impact of cannabinoids in street cannabis on cognition, psychotic-like symptoms and psychological well-being. Psychol. Med. 42, 391-400. doi: 10.1017/S0033291711001322

Morgan, C. J., Schafer, G., Freeman, T. P., and Curran, H. V. (2010). Impact of cannabidiol on the acute memory and psychotomimetic effects of smoked cannabis: naturalistic study: naturalistic study [corrected]. Br. J. Psychiatry 197, 285-290. doi: 10.1192/bjp.bp.110.077503

Munro, S., Thomas, K. L., and Abu-Shaar, M. (1993). Molecular characterization of a peripheral receptor for cannabinoids. Nature 365, 61-65. doi: 10.1038/ $365061 \mathrm{a} 0$

Murray, R. M., Englund, A., Abi-Dargham, A., Lewis, D. A., Di Forti, M., Davies, C., et al. (2017). Cannabis-associated psychosis: neural substrate and clinical impact. Neuropharmacology 124, 89-104. doi: 10.1016/j.neuropharm.2017. 06.018

National Academies of Sciences (2017). The Health Effects of Cannabis and Cannabinoids: the Current State of Evidence and Recommendations for Research. Washington, DC: The National Academies press.

O’Neill, A., Wilson, R., Blest-Hopley, G., Annibale, L., Colizzi, M., Brammer, M., et al. (2020). Normalization of mediotemporal and prefrontal activity, and mediotemporal-striatal connectivity, may underlie antipsychotic effects of cannabidiol in psychosis. Psychol. Med. 29, 1-11. doi: 10.1017/S0033291719003519

Papanti, D., Schifano, F., Botteon, G., Bertossi, F., Mannix, J., Vidoni, D., et al. (2013). "Spiceophrenia": a systematic overview of "spice"-related psychopathological issues and a case report. Hum. Psychopharmacol. 28, 379389. doi: 10.1002/hup. 2312

Pavlovic, R., Nenna, G., Calvi, L., Panseri, S., Borgonovo, G., Giupponi, L., et al. (2018). Quality traits of "cannabidiol oils": cannabinoids content, terpene fingerprint and oxidation stability of European commercially available preparations. Molecules 23:E1230. doi: 10.3390/molecules23051230

Pertwee, R. G. (2008). The diverse CB1 and CB2 receptor pharmacology of three plant cannabinoids: delta9-tetrahydrocannabinol, cannabidiol and delta9tetrahydrocannabivarin. Br. J. Pharmacol. 153, 199-215. doi: 10.1038/sj.bjp. 0707442

Rigucci, S., Marques, T. R., Di Forti, M., Taylor, H., Dell'Acqua, F., Mondelli, V., et al. (2016). Effect of high-potency cannabis on corpus callosum microstructure. Psychol. Med. 46, 841-854. doi: 10.1017/S0033291715002342

Rognli, E. B., Berge, J., Hakansson, A., and Bramness, J. G. (2015). Long-term risk factors for substance-induced and primary psychosis after release from prison. A longitudinal study of substance users. Schizophr. Res. 168, 185-190. doi: 10.1016/j.schres.2015.08.032

Rossler, W., Hengartner, M. P., Angst, J., and Ajdacic-Gross, V. (2012). Linking substance use with symptoms of subclinical psychosis in a community cohort over 30 years. Addiction 107, 1174-1184. doi: 10.1111/j.1360-0443.2011.03760. $\mathrm{x}$

Rothmond, D., Weickert, C., and Webster, M. (2012). Developmental changes in human dopamine neurotransmission: cortical receptors and terminators. $B M C$ Neurosci. 13:18. doi: 10.1186/1471-2202-13-18

Sachs, J., McGlade, E., and Yurgelun-Todd, D. (2015). Safety and toxicology of cannabinoids. Neurotherapeutics 12, 735-746. doi: 10.1007/s13311-015-0380-8

Sami, M. B., Rabiner, E. A., and Bhattacharyya, S. (2015). Does cannabis affect dopaminergic signaling in the human brain? A systematic review of evidence to date. Eur. Neuropsychopharmacol. 25, 1201-1224. doi: 10.1016/j.euroneuro. 2015.03.011

Schoeler, T., Kambeitz, J., Behlke, I., Murray, R., and Bhattacharyya, S. (2016a). The effects of cannabis on memory function in users with and without a psychotic disorder: findings from a combined meta-analysis. Psychol. Med. 46, 177-188. doi: 10.1017/S0033291715001646

Schoeler, T., Petros, N., Di Forti, M., Klamerus, E., Foglia, E., Ajnakina, O., et al. (2016b). Effects of continuation, frequency, and type of cannabis use on relapse in the first 2 years after onset of psychosis: an observational study. Lancet Psychiatry 3, 947-953. doi: 10.1016/S2215-0366(16)30188-2

Schoeler, T., Petros, N., Di Forti, M., Pingault, J. B., Klamerus, E., Foglia, E., et al. (2016c). Association between continued cannabis use and risk of relapse in firstepisode psychosis: a quasi-experimental investigation within an observational study. JAMA Psychiatry 73, 1173-1179. doi: 10.1001/jamapsychiatry.2016.2427

Schreiner, A. M., and Dunn, M. E. (2012). Residual effects of cannabis use on neurocognitive performance after prolonged abstinence: a meta-analysis. Exp. Clin. Psychopharmacol. 20, 420-429. doi: 10.1037/a0029117

Scott, J. C., Slomiak, S. T., Jones, J. D., Rosen, A. F. G., Moore, T. M., and Gur, R. C. (2018). Association of cannabis with cognitive functioning in adolescents and young adults: a systematic review and meta-analysis. JAMA Psychiatry 75 , 585-595. doi: 10.1001/jamapsychiatry.2018.0335

Small, E. (2015). Evolution and classification of cannabis sativa (marijuana, hemp) in relation to human utilization. Bot. Rev. 81, 189-294. doi: 10.1007/s12229015-9157-3

Sneider, J. T., Mashhoon, Y., and Silveri, M. M. (2013). A review of magnetic resonance spectroscopy studies in marijuana using adolescents and adults. J. Addict. Res. Ther. doi: 10.4172/2155-6105.S4-010 [Epub ahead of print].

Solowij, N., Broyd, S., Greenwood, L. M., van Hell, H., Martelozzo, D., Rueb, K., et al. (2019). A randomised controlled trial of vaporised $\Delta 9$ tetrahydrocannabinol and cannabidiol alone and in combination in frequent and infrequent cannabis users: acute intoxication effects. Eur. Arch. Psychiatry Clin. Neurosci. 269, 17-35. doi: 10.1007/s00406-019-00978-2

Taurisano, P., Antonucci, L. A., Fazio, L., Rampino, A., Romano, R., Porcelli, A., et al. (2016). Prefrontal activity during working memory is modulated by the interaction of variation in $\mathrm{CB} 1$ and $\mathrm{COX} 2$ coding genes and correlates with 
frequency of cannabis use. Cortex 81, 231-238. doi: 10.1016/j.cortex.2016.05. 010

Thomas, A., Baillie, G. L., Phillips, A. M., Razdan, R. K., Ross, R. A., and Pertwee, R. G. (2007). Cannabidiol displays unexpectedly high potency as an antagonist of CB1 and CB2 receptor agonists in vitro. Br. J. Pharmacol. 150, 613-623. doi: $10.1038 /$ sj.bjp. 0707133

Tien, A. Y., and Anthony, J. C. (1990). Epidemiological analysis of alcohol and drug use as risk factors for psychotic experiences. J. Nerv. Ment. Dis. 178, 473-480.

van Os, J., Bak, M., Hanssen, M., Bijl, R. V., de Graaf, R., and Verdoux, H. (2002). Cannabis use and psychosis: a longitudinal population-based study. Am. J. Epidemiol. 156, 319-327. doi: 10.1093/aje/kwf043

Volk, D. W., and Lewis, D. A. (2016). the role of endocannabinoid signaling in cortical inhibitory neuron dysfunction in schizophrenia. Biol. Psychiatry 79, 595-603. doi: 10.1016/j.biopsych.2015.06.015

Weiser, M., Knobler, H. Y., Noy, S., and Kaplan, Z. (2002). Clinical characteristics of adolescents later hospitalized for schizophrenia. Am. J. Med. Genet. 114, 949-955. doi: 10.1002/ajmg.10647

Whiting, P. F., Wolff, R. F., Deshpande, S., Di Nisio, M., Duffy, S., Hernandez, A. V., et al. (2015). Cannabinoids for medical use: a systematic review and meta-analysis. JAMA 313, 2456-2473. doi: 10.1001/jama.2015.6358

Wiles, N. J., Zammit, S., Bebbington, P., Singleton, N., Meltzer, H., and Lewis, G. (2006). Self-reported psychotic symptoms in the general population: results from the longitudinal study of the British National Psychiatric Morbidity Survey. Br. J. Psychiatry 188, 519-526. doi: 10.1192/bjp.bp.105.012179

Wilson, R., Bossong, M. G., Appiah-Kusi, E., Petros, N., Brammer, M., Perez, J., et al. (2019). Cannabidiol attenuates insular dysfunction during motivational salience processing in subjects at clinical high risk for psychosis. Transl. Psychiatry 9:203. doi: 10.1038/s41398-019-0534-2

Zammit, S., Allebeck, P., Andreasson, S., Lundberg, I., and Lewis, G. (2002). Self reported cannabis use as a risk factor for schizophrenia in Swedish conscripts of 1969: historical cohort study. BMJ 325:1199. doi: 10.1136/bmj.325.7374.1199
Zehra, A., Burns, J., Liu, C. K., Manza, P., Wiers, C. E., Volkow, N. D., et al. (2018). Cannabis addiction and the brain: a review. J. Neuroimmune Pharmacol. 13, 438-452. doi: 10.1007/s11481-018-9782-9

Zou, S., and Kumar, U. (2018). Cannabinoid receptors and the endocannabinoid system: signaling and function in the central nervous system. Int. J. Mol. Sci. 19:833. doi: 10.3390/ijms19030833

Zuardi, A., Crippa, J., Dursun, S., Morais, S., Vilela, J., Sanches, R., et al. (2010). Cannabidiol was ineffective for manic episode of bipolar affective disorder. J. Psychopharmacol. 24, 135-137. doi: 10.1177/02698811080 96521

Zuardi, A. W., Crippa, J. A., Hallak, J. E., Pinto, J. P., Chagas, M. H., Rodrigues, G. G., et al. (2009). Cannabidiol for the treatment of psychosis in Parkinson's disease. J. Psychopharmacol. 23, 979-983. doi: 10.1177/02698811080 96519

Zuardi, A. W., Hallak, J. E., Dursun, S. M., Morais, S. L., Sanches, R. F., Musty, R. E., et al. (2006). Cannabidiol monotherapy for treatment-resistant schizophrenia. J. Psychopharmacol. 20, 683-686. doi: 10.1177/0269881106060967

Zuardi, A. W., Morais, S. L., Guimarães, F. S., and Mechoulam, R. (1995). Antipsychotic effect of cannabidiol. J. Clin. Psychiatry. 56, $485-486$.

Conflict of Interest: The authors declare that the research was conducted in the absence of any commercial or financial relationships that could be construed as a potential conflict of interest.

Copyright (c) 2020 Colizzi, Ruggeri and Bhattacharyya. This is an open-access article distributed under the terms of the Creative Commons Attribution License (CC BY). The use, distribution or reproduction in other forums is permitted, provided the original author(s) and the copyright owner(s) are credited and that the original publication in this journal is cited, in accordance with accepted academic practice. No use, distribution or reproduction is permitted which does not comply with these terms. 